\title{
Bob Ham (1937-2012): A Pioneer in Waste Management
}

This special issue of Waste Management is a series of papers in memory of Bob Ham. The papers are by former students and close colleagues, and also by researchers following along the paths blazed by Bob. As a preface to these papers, and a tribute to his memory, a number of contributors have provided their reflections.

Robert Ham was born in 1937 in Minnesota, and grew up there, receiving his Bachelor's in Chemical Engineering from the University of Minnesota in 1960. After working briefly, he studied at the University of Washington, receiving his Masters in Chemical Engineering and his PhD in Environmental Engineering. From 1967 to 1998 he was a faculty member at the University of Wisconsin-Madison. After a long career and numerous publications, his high-impact contribution was recognised by receipt of the "Life for Waste" award at the 2003 Sardinia Symposium.

Anders Lagerkvist (Lulea University of Technology) recalls:

I met Bob for the first time at SARDINIA 1987. Having read some of his publications and learned from them, it was a pleasure to find that the author was not only an inspiring researcher but also a friendly and down-to-earth person who actually enjoyed speaking to a PhD student like me just as much as anybody else. The following year I met him again, at a seminar in Switzerland, where he not only remembered me, but introduced me to other colleagues with the air of having known me for ages. This is an aspect of Bob's legacy that is important, but not visible from a list of his publications: he was a great bridge builder, notably between European and American researchers. I saw in action a truly independent thinking, humble and friendly person. Bob was a true friend.

As I started my research group in the late eighties, Bob gave advice, visited our group, and reviewed the work of my PhD students, listening to all. He gave positive and negative critique in a constructive manner, and also made us all feel that we were a part of a global continuum.

Raffaello Cossu (University of Padova and Editor-in-Chief of Waste Management) writes:

I met Bob through ISWA's Working Group on Landfills in 1986. Rainer Stegmann, Thomas Christensen, Peter Lechner, Anders Lagerkvist and Luis Diaz were also part of the group at that time, all of whom eventually drifted away from ISWA and went on to found IWWG. The group was also made up of Stan Verrier from South Africa. Stan invited us to visit South Africa. Apartheid still existed at that time.

We spent two weeks there visiting research centres, universities and several landfills. I most remember Bob for his response to the Mayor of Pretoria's welcome speech. "A few days ago we visited a landfill in Soweto (a slum inhabited exclusively by black people) and noticed a significant difference in the composition of waste as opposed to white areas. We wish and hope for South Africa's waste to have the same composition as soon as possible!" His words were met with a forced smile by the Mayor and a tepid applause by his coworkers: touché! 
Rainer Stegmann (President of IWWG) provides a similar reflection on Bob's bridgebuilding:

Bob Ham visited me at the Technical University in Braunschweig, Germany in 1974. He was especially interested in our work on leachate treatment. Some months later he asked me if I would be interested to work with him as a post- doc on an EPA project to develop a leaching test procedure for waste. After finishing my PhD I came to Madison in 1976. During our project, he provided great support but also academic freedom. I still recall our inspiring, and sometimes controversial, discussions.

Bob arranged for me to meet with important US and Canadian scientists in the field of waste management. Of greatest importance to me was the introduction into the field of landfill gas extraction. There was not much activity in LFG in Germany at that time but this changed when I came back to Germany, reporting about the great success of this activity in the US. The invitation to come to Madison had an enormous influence on my personal and academic life. I am very grateful that I met this very intelligent, creative scientist, who was also a friendly and helpful person.

Bob led a number of projects that are valuable to both researchers and practicing engineers today. Morton Barlaz (North Carolina State University) reflects:

I began graduate school in 1982 and had the good fortune to have Bob Ham offer me an assistantship to work on refuse decomposition. I asked if doing my Master's degree in the area of solid waste would mean that I would be stuck for my whole career in solid waste. He assured me that this was not necessarily the case but 30 years later I am still working in the area of solid waste and enjoying every minute!

Bob was the first to work on the loss of biodegradable organic matter in refuse and developed the cellulose to lignin ratio as an indicator of waste decomposition. Because lignin is recalcitrant while cellulose degrades in landfills, the ratio decreases as waste decomposes. The beauty of this ratio is that the presence of soil in a waste sample has no impact, making it ideal for landfills.

Bob was also a leader in the development of landfill gas to energy projects. As a graduate student, I remember Bob's many trips to the west coast to assist the emerging industry. This industry has matured throughout the world today from those pioneering efforts of Bob and others in the late 70 s and early 80 s.

I am honored by the opportunity to remember Bob and to build on the foundation that he helped to establish.

Dimitris Komilis (Democritus University of Thrace) also recalls Bob's research accomplishments:

I went to the US for graduate work in 1993. Although I worked on an area where Bob had not been actively involved (composting). Bob always stated that solid waste experiments should take place in large scale reactors. He had huge consulting experience on solid waste management issues and performed some of the most classic solid waste (pilot and field scale) anaerobic experiments. I will also remember him for his advice that I should not worry too 
much, for his dislike towards emails, and for his love of big motorcycles and old cars. I am truly grateful that I worked with Bob, who has highly influenced my research and teaching.

That emphasis on field-scale experiments necessarily required someone like Bob who could assemble teams to work on large problems, developing new protocols as needed to overcome the many practical problems of delivering valuable results with heterogeneous, unpleasant, everyday solid waste.

The practical application of new knowledge was always important to Bob. This is well demonstrated by the reminiscence of Carol Diggelman (Professor Emeritus, Milwaukee School of Engineering):

Bob Ham was my PhD advisor on "Life Cycle Comparison of Five Engineered Systems for Managing Food Waste", a comprehensive environmental evaluation of food waste disposer (FWD) impacts to wastewater and solid waste management systems. We analyzed actual Madison-area facilities that would be impacted by FWD use-rural on-site wastewater systems, the urban sewage system, the solid waste collection system, the regional landfill, RDF and composting facilities.

After the project was completed, Bob Ham was invited to give expert testimony to the Housing Committee of the New York City Council. He summarized industry studies, including this study, on FWD impacts to wastewater treatment plants. Bob was able to simplify and make the research results understandable, while still communicating the strong technical basis of the results. He didn't talk down to his audience and illustrated his points with practical examples. About three months later, the New York City Council voted to lift the FWD ban.

I owe Bob Ham a debt of gratitude for the opportunity to work on this project. His contributions to the field of solid waste management are many and they are his legacy.

Bob is also remembered for his pioneering work to bring solid waste practitioners and researchers together. He was instrumental in the success of the Madison Waste Conferences of the 1980s and 1990s. He also taught numerous professional education courses on solid waste management explaining new and emerging solid waste principles to a wide variety of practitioners. Phillip O'Leary, who worked with Bob Ham for many years on continuing education courses and the Madison Waste Conferences, writes:

Professor Ham's research provided guidance in fundamental ways that artfully explained field observations that were previously poorly understood or simply mysterious. As an instructor in the UW's continuing education programs, where I had the pleasure of working directly with him for many years, he educated thousands of practicing professionals.

The students he taught lead waste handling companies, run public service agencies, supervise regulatory agencies, operate consulting firms, and conduct world-class research. We should acknowledge that Professor Ham's teaching is a significant part of his legacy.

I was a Masters student of Bob Ham in the mid-1980s researching waste decomposition. One important part of Bob's legacy is the impact of his teaching. When I took his undergraduate course in Solid Waste Management, the classroom was packed. That was a 
testament to Bob's ability to teach in a way where students were exposed to the latest ideas and shown their practical value. Bob's landfill design assignment was a closely co-ordinated project where students could achieve a relatively large, integrated engineering design in a short period of time. For students like me, who were accustomed to a series of distinct calculations, it was a revelation to find that the depth of my landfill had to change after I refined my estimate of daily cover requirements, and that the whole design process was an iterative rather than a linear process. When I started teaching Solid Waste Management here, one of the key parts that I introduced was a Landfill Design assignment.

Bob had a personal style too often missing today. Jean Bogner (University of Illinois at Chicago) recounts:

Bob was a great midwestern Wisconsin guy. He was always congenial, courteous and helpful to students, researchers, regulators, landfill owners and operators. He formed long-standing relationships, often lasting for decades. Bob was committed to field-validated research, and we agreed strongly on the importance of developing meaningful field-scale results. He will be missed.

Just as a list of research papers and accomplishments cannot summarise a life's work, neither can a limited number of reminiscences from colleagues and friends. We touch many lives in many different ways-professionally and personally. We ourselves benefit from taking the opportunities to acknowledge the impacts others have on us. It is hoped that this special issue will encourage readers to reflect on the impact others have on our work, and the impact we have on those who will follow.

I close with this comment from Anders Lagerkvist:

In my view, Bob stood for many of the virtues of a true researcher: independent thinking, critical examination, openness, and stamina. All of us who had the privilege to know him will continue to draw strength from that, and hopefully inspire others.

Mark Milke

Department of Civil and Natural Resources Engineering University of Canterbury

Christchurch, New Zealand 